\title{
Arte y visualización en los nuevos medios, una estrategia de dislocación del sentido y la identidad
}

Francisco Gerardo Toledo Ramirez Universidad Autónoma Metropolitana - México 


\section{Resumen}

La inclusión de tecnología digital en la visualización de objetos de arte condujo este proceso a su consecuencia natural, liberando y demostrando que nuestra confianza en la objetividad y consistencia cartesiana de la fotografía en la representación de la naturaleza, no podía seguir siendo válida en terminos de nuestras nociones sobre el significado-espacio-tiempo como sistema cerrado; interactividad y virtualidad han demostrado que en el núcleo del arte digital y del site de arte de internet, residen las conversiones o transformaciones de la imagen (las artísticas entre las más importantes) en un sistema abierto. Esas nuevas formas de producir y percibir los objetos de arte nuevos, requiere la emergencia de nuevas sensibilidades y paradigmas relacionadas con nuevos valores cognitivos y artísticos contemporáneos una nueva tecnoestesia, como la denominan E. Couchot y otros.

\section{Palabras-clave}

identidad, dislocación, permutación, ubicuidad, deconstrucción y transmutación

\section{Abstract}

The added digital technology in visualization of art objects has just led that process further towards its natural consequences. It has liberated and demonstrated that our confidence in the objectivity and cartesian consistency of the photographic representation of nature is no longer valid, at least in terms of our traditional notions of a meaning-timespace closed system. Interactivity and virtuality has demonstrated that at the core of digital and website art resides the transformation of the images (artistic creations among the most important) into an open system. These new ways of producing and receiving art objects require emergent sensibilities and paradigms regarding the latest contemporary cognitive and artistic values, a new technesthesia as named by E. Couchot and others.

\section{Key words}

identity dislocation, permutation, ubiquity, deconstruction, transmutation processes, virtuality, interactivity 


\section{Hipervelocidad estática}

sobre el arte de conseguir ravioles on line

ué significa visualizar?, ¿qué secreto motor mágico está
escondido bajo el pensamiento y la obra de un artista
visual?. ¿Es rigurosamente cierto que el artista nos "re-
vela" una realidad por medio de visiones, a las que dificilmente accederíamos, de no ser por su mediadora intervención?; ¿es en este sentido el artista un demiúrgo y un mago?, ¿o un intermediario y un medio de canalización del mensaje, es ambos?. Y, ¿cómo se construye este mensaje?, ¿cómo intervienen los instrumentos y los materiales de que se vale el creador?, ¿cómo incorpora hoy información, noticias, discursos, imágenes documentales o poéticas captadas digitalmente y en video, espacios virtuales que ni siquiera existen realmente?, ¿cómo incorpora ideas sobre las cosas, ideas sobre las ideas de las cosas, ideas sobre las ideas de las ideas de las cosas?, ¿en qué momento redirige su atención de lo qué estaba diciendo a lo que quiere decir, o a lo que desearía decir, con otras herramientas, otros utensilios, otras técnicas, otro espacio-tiempo?

La antinomia entre artes y técnicas herencia del S. XIX, ha quedado rebasada ya hace tiempo, pero nunca mejor que ahora, la producción plástica contemporánea digital o no, ha demostrado que las así llamadas técnicas no son únicamente modos de producción, sino también modos de percepción; en particular en el arte asistido o creado por ordenador, esas técnicas pueden ser llamadas también ( $\sin$ temor a exagerar), modos de configuración sintáctica. Por ejemplo el Digital \& Web art, parece comprobar que la "autoría" y la identidad de la obra de arte son potencialmente menos consistentes (¿importantes?) de lo que nos gusta -por tradición- pensar, el 
$C D$ ROM de arte y la instalación multimedia exhiben una estética nueva que reclama un pensar haciendo y un hacer pensando diferentes, muy lejos de la cadena de montaje lineal de sentido, (temacontenido, técnica-ejecución, exhibición-consumo) donde la realización final, la materialización de la visión era ejecutada con diversos modos de producción llamadas técnicas (Couchot, 1989).

La computadora personal, pasó muy rápido por esa falsa identidad (ser sólo el implemento de la"salida" de la obra), el paso de lo analógico a lo digital en el contexto de la producción artística señalada líneas arriba, fué posible -más allá de los aspectos tecnológicos-gracias a que tanto la computadora como la infraestructura teleinformática digital son (hoy), al mismo tiempo, modo. de concepción. mnic de análisis-deconstrucción, modo de sintesis-configuración, modo de uifusinn!-consum.o. La visión de la computadora como herramienta quedó atrás de la misma forma en que el retrato hablado se parecía poco al asesino. Es más adecuado hoy en día pensar en un "instrumento", a la manera de los objetos para hacer música, un instrumento musical digamos un saxofón está ahí en el sofá, cualquiera con curiosidad, sensibilidad y audacia, puede empezar a hacer "algo" con él. Ahora bien si se sabe escribir y leer música, si se tienen dedos ágiles, fantasía e ideas profundas, los resultados crecerán exponencialmente. Lo mismo sucede con las computadoras personales.

Esta multiplicidad de funciones (modo de concepción, modo de análisis-deconstrucción, modo de sintesis-configuración, modo de difusión-consumo) corresponde elocuentemente a las transmutaciones espacio-temporales características del Web, la realidad virtual o la hipertextualidad, con rasgos y consecuencias importantísimas en el quehacer plástico, como bien lo señala Christine Desrochers:

... Cette nouvelle expérience technesthésique -le site d'art internet-opére des mouvements importants dans l'expérience spatio-temporelle de la chose artistique. En effet ces cuvres numériques ne sont pas figées dans le temps et l'espace comme un tableau ou encore une 
photographie. Ces æuvres instaurent un présent qui n'a jamais existé et qui ne se répétera jamais systématiquement. Le concept d'uchronicité, tel que défini par Couchot, résume bien cette réalite temporelle propre au site d'art internet: L'action du regardeur détermine la durée de l'œuvre et sa structure dans le temps.

...esta nueva experiencia tecnoestésica - el site de arte en Internet-, opera movimientos importantes en la experiencia espacio-temporal del objeto artístico. En efecto, estas obras digitales (numéricas), no se encuentran fijas en el espacio-tiempo como un cuadro o una fotografía. Esta obras instauran un presente que jamás existió y que no se repetirá nunca sistemáticamente. El concepto de ucronicidad, tal como lo define Couchot resume bien esta realidad temporal propia del site de arte en Internet: la acción del observador determina la duración de la obra y su estructura en el tiempo (cf., Couchot, 1989).

Numerosas obras artísticas en el Web hacen referencia directa o indirectamente, más o menos explícitamente a esa potencialidad en curso espacio-temporal que permite navegar el Web, tal flexibilidad espacial instaurada por el espacio virtual y el hipertexto, contradiciendo en cierta forma ideas sobre el tiempo como las de S. Hawking (el tiempo de hecho no existe, es una mera sensación, dice Hawking), de hecho quizas los artistas digitales están demostrando en sentido inverso, la sensación de que estamos hechos de tiempo (homo historicus), que somos seres cuya sustancia es el tiempo.

O bien - con mayor pertinencia, en el dominio semiótico-, comprobando una concepción fenomenológica de él elaborada por Merleau-Ponty, según la cual deberíamos pensar el espacio como la puissance universelle de connexion entre les choses -la potencia universal de conexión entre las cosas (Merleau-Ponty, 1945) ${ }^{1}$.

1. Según Merleau-Ponty, deberíamos pensar el espacio no como el medio real o lógico en el que se disponen las cosas, sino el medio por el cual la posición de las 


\section{Tercer ojo ciego}

regiones residuales y la decadencia del arte de la reposteria

A lo largo de la historia el hombre ha ideado tres artilugios como formas de control del tiempo: el reloj, la cámara fotográfica y la máquina del tiempo. El reloj puntea e imprime una medida al transcurso de las horas y los minutos. La cámara fotográfica detiene el tiempo y congela el movimiento. Y la máquina del tiempo, según la fabulación de H.G. Wells nos permite viajar hasta donde queramos del pasado o del futuro (Fontcuberta, 1998).

De esta manera Joan Fontcuberta estructura una interesante $\checkmark$ :sión de los artistas trabajando con los medios digitales, fundamentalmente la gráfica digital, la fotografía intervenida digitalmente, la realidad virtual, el modelado $3 \mathrm{D}$, etc. según esta visión son, la identidad y la dislocación espacio-temporal, las claves que hay que estiriar con mayor profundidad, por un razón capital: de la misma manera en que la fotografia emancipó a la pintura de la representación realista, hoy las tecnologías digitales le devuelven el favor a la fotografía, emancipándola de la pretendida objetividad real, como memoire de lumiere, pencil of nature, etc.

Veamos brevemente un panorama de la revolución óptica desde el s. XIX hasta nuestros días, que nos permita articular en perspectiva, cuál es la aportación a la visualización, a los nuevos modos de ver, que la tecnología digital en el trabajo de los artistas contemporáneos está produciendo.

La visión técnica, más que la técnica de la visión nos fué heredada por la revolución óptica del s. XIX. Tal visión técnica en occidente nos fue algo menos impuesta, que la idea misma de ella, en otras palabras las vanguardias artísticas de final del s. XIX, y principio del s. XX, transvasaron una sensibilidad especial en torno a las máquinas y la tecnología dentro de la experiencia humana, la idea del futuro -y en ello la obra de arte desde las vanguardias tuvo mucho que ver-como "utopía" tecnocientífica, como culto de la velocidad y

cosas resulta posible, como La puissance universelle de connexion entre les choses, la potencia universal de conexión entre las cosas. 
la multiplicidad-mutabilidad, como amalgama de los principios apolíneo y dionisiaco en un legado plástico nuevo, fueron junto con el cinematógrafo y la televisión los paradigmas nuevos que modelaron en el s. XX nuestra idea de la visión y la visualización.

La revolución óptica del s. XIX, priorizó a la vista como el sentido dominante de la percepción humana, codo a codo, aunque las convenciones de la epoca los separasen más que declaradamente, científicos y pintores nos brindaron toda una serie de experiencias, objetos, instrumentos y procedimientos para desglozar, analizar, deconstruir y "repensar" la visión, mediante la tecnovisión (aparatos para generar, transmitir y reproducir las imágenes) y la pinturapintura (objetos de arte que reclamaban una nueva forma de "ver", y de "ser vistas"). Todo un vasto vocabulario visual cuyo objetivo inicial no era el de crear el arte del movimiento, sino el arte de ver, según Peter Weibel

...nos enseñaron a ver de modo diferente con maquinas, revelando un mundo de imágenes que no se podrían haber visto ni creado sin ellas. Crearon una escritura de la visión, la opseografía, en vez de una escritura del movimiento (cine), observaron la visión, desarrollaron las técnicas para VER la visión, la opseoscopía. (Weibel, 1998).

Dos principios fundamentales fueron legados iconográficamente al finalizar el siglo XIX:

- El nacimiento de lo visual, como resultado de la dicotomización de Imagen y Visión.

- El nacimiento de la cultura telemática, como resultado de la nueva realidad inmaterializada de los signos.

En el primer caso, si antes de la fotografía, una Imagen era una pintura, ahora, la "visualidad", debe extenderse abarcando otras expresiones; fotografía, cine, TV y video más adelante. Imagen y Visión se bifurcan, se dicotomizan, el encuentro entre la imagen y los medios técnicos produjo el nacimiento de lo "visual". Sin esta "extensión" de lo visual no es posible comprender los orígenes y evolución del arte digital. 
En el segundo casola división cuerpo y mensaje que produjo la telegrafía (y el principio de escaneo, hacía 1840 -de pronto un mensaje podía ser enviado sin mediación de un vehículo físico, material un caballo, un soldado, un barco) condujo a la consolidación de una cultura telemática, el mundo inmaterial de los signos en el que las cadenas de significación podían viajar (ahora) "sin" un cuerpo físico, la forma espacial, bidimensional de un escrito o una imagen se transformaba en una forma temporal. Sin la cultura telemática, la información que deviene espectáculo no sería, como lo es en la actualidad el eje de construcción sintáctica en el arte creado por computadora o con tecnología digital. Esta permutabilidad antecede la flexibilidad espacio-temporal y la naturaleza articulante (connexion entre les choses) de la idea del espacio de la que habla MerleauPonty, presente más tarde en el Web y la teleinformación, en la que la conversión -dentro del dominio de la tecnología electrónica- de los dispositivos analógicos a los digitales, tuvo inevitablemente lugar. Si la fotografía, liberó a la pintura de la necesidad de representar la naturaleza, el cinematógrafo y más tarde la TV, liberarían al teatro de la necesidad de "representar" la teatralidad, el teatro así se abrió a un terreno espacio-temporal distinto, íntimo o público, culto o popular, pero diferente.

De manera análoga a la inmaterialidad de los signos telegráficos, los grandes creadores teatrales vislumbraron la posibilidad de refundar un arte nuevo, en el que no necesariamente estuviesen los vehículos físicos de los mensajes, no sólo las escenografías y decorados eran susceptibles de ser reformulados, sino la gestualidad misma de los actores, que la edición cinematográfica había revelado deconstruyéndola, para configurar nuevas unidades expresivas, la continuidad gestual-espacio-temporal a la luz de una nueva estética nos ofrecería el teatro de la ruptura y de la vanguardia, avanzada la primera mitad del s. XX. De la misma forma que la fotografía lc dió (de regre:so) a la pintura un sentido más (el de la autopresencia) y una reubicación espacio-temporal-temática más plena, el cine y la $\mathrm{TV}$, le dieron al teatro (de regreso), un lenguaje auspliado que fue detectado sólo por los autores más sensibles y capaces de entender que las muertes decretadas (la de la pintura cuando apareció la fotografía, la del teatro cuando apareció el cine) eran en realidad, 
oscilaciones de la natural flexibilidad del matrimonio techne/episteme, por ello se habla en el momento actual de una nueva visualidad (con propiedad la visualización digita)l como el dominio de una tecnoestesia digital, como lo establecen E. Couchot, P. Virilio, J. Perry Barlow, $P$. Weibel y otros; por cierto el final del s. XX, vió en la tecnología digital y el arte contemporáneo una nueva oscilación, (verdadera dislocación de sentido e identidad) en la que el Diseño (fundamentalmente el gráfico), le dá (de regreso) a la pintura no sólo herramientas y técnicas, sino espacios de concepción inéditos vía la digitalización y una nueva densidad epistemológica. Esta nueva (siguiente) mutación es análoga a la sintáxis y retórica visual creada a principios y mediados del s. XX por la fotografía, el cine y, más tarde por el video, los artistas utilizando estos medios aportaron una concepción revolucionaria de lo visual y de la visualización tanto más propia en la medida en que la dicotomía arte/técnica fué abandonada en favor de una relatividad espacio-temporal diferente, en la medida en que las "visiones" interiores adquirieron el rango de artisticidad actual.

Al desprenderse de la función estética asignada como herencia tecnovisiva del s. XIX como pencil of nature, la fotografía permitió a los artistas comprobar la naturaleza del espacio-tiempo como la entiende Merleau-Ponty, "la puissance universelle de connexion entre les choses". La articulación de una nueva concepción mental en la que se pasa (literal y metafóricamente) del espacio espacializado al espacio espacializante, es un proceso que comenzó con la edición cinematográfica, maduró con la TV y el videoarte y encontró su entorno natural a principio de los 90 , con el digital art; detonando la experimentación más fecunda con la información, los dispositivos computacionales, la realidad virtual el site de arte en internet, etc., el eje conceptual clave está identificado por dos términos: interactividad y virtualidad.

Interactividad no sólo convirtiendo al espectador en autorpartícipe-usuario, sino trasladando la experiencia sintáctica-conceptual al terreno de la no linealidad hipertextual y la autoría colectiva o transmutante. Virtualidad no sólo en la reetructuración del speculum mundi por vía de una realidad paralela o ciberespacio, donde se dan nuevos escenarios y partituras estetizantes, sino además confirmando lo que Evgene Bavcar, el extraordinario fotografo ciego ya sabía: 
...la ampliación (ilusoria) del mundo de la vista, provoca una expansión recíproca del mundo invisible. Quizás esta dialéctica implacable debe ser aceptada para poder rechazar la noción de la supuesta capacidad del hombre moderno para la vista infinita, noción demasiado servil a la ideología de la técnica. Yo distingo entre la luz (lumiére) y el alumbramiento (éclairage): los juegos de la luz son para mí los velos que nos impiden alcanzar lo real. ... Nuestro deseo de imágenes es, entonces, nuestra respuesta a la existencia de un tercer ojo que está al tanto de nuestra mirada física, como dice Kazantzakis): "de nuestros ojos de barro que no pueden ver lo invisible" (cita de Bavcar).

Sólo el tercer ojo tiene el privilegio de yer cada vez más allá. (Mayer Foulkes, 1999).

\section{1 digital art}

una economía espacio-temporal

El siglo XX es considerado como el de la imagen y la información y con cierta ironía a partir de la segunda mitad, el de la iconización-fetichización vía la conversión de la realidad en espectáculo de masas y de la conversión de éste en la realidad. Si el s. XIX nos legó la adicción a la movilidad, la visión y la reproductibilidad por medio de la tecnificación y taxonomía de la visión, el s. XX promovió el hiperdesarrollo de los instrumentos y procedimientos para individualizar la "propiedad" de la experiencia visual. Por medio de la retórica cinematográfica y después televisiva, las sucesivas olas de inclusión en la práctica artística de las técnicas y máquinas de la visión y el análisis de datos, verdaderas articulaciones vinculantes del espacio-tiempo, mediante las técnicas y tecnologías que inevitablemente habían hecho posible la miniaturización de los dispositivos electrónicos y más tarde la digitalización de la información, crearon en primera instancia la ilusión de un poder expandido en la apropiación de la experiencia visiva. Si Duchamp había demostrado que el objeto artístico podía ser la idea que se tiene de él y que el espectador podía ser también autor interviniendo para "completar" 
la obra artística (piénses por ejemplo en la obra en colaboración con Man Ray, Rotary glass plates (precision optics), 1920), era entonces palpable lo anacrónico que resultaba entender el avance plástico como sólo una secuencia de movimientos o ismos y sus respectivos "manifiestos". En realidad las experimentaciones más profundas, por vía racional o expresiva-sentimental apuntaban a un mismo lugar, un espacio tal vez interior como la visión de los sueños o esa metarealidad ya percibida por algunos pintores, metafísicos y surrealistas, a un sitio donde el continuum espacio-temporal no se daba en forma convencional, sino que se abría en capas y espirales, particularizando la sensación perceptiva -una suerte de tercer ojo potenciado por la tecnología- vía el exceso o el extasis, en el que la interacción, mente-lenguaje, discurso-lectura, contenido-autor-perceptor despunta como un proceso clave, decíamos provocando la ilusión de un poder ampliado en la apropiación de la experiencia de lo visual. Por vía expresiva o bien conceptual/racional los artistas habían detectado y trabajado con este proceso; paralelamente la ciencia, la tecnología (de guerra, hay que decirlo), la teleinformación y miniaturización electrónica habían hecho lo propio.

A finales de la década de los 40 , las bases tecnológicas que harían posible la computadora personal en los 70 estaban dadas, la digitalización de la materia prima de la visión (la idea misma de "lo visible, la visualización") pasaba de ser mera especulación científica en componente natural de la experimentación plástica a partir de que fué técnicamente y económicamente posible -a principios de los años 70 - realizarla, por otra parte tanto el estudio de las leyes de la percepción, como los procesos cognitivos, los modos de ver, las relaciones entre éstas y la transmisión de la información era ya suficientemente profundo en esos años.

Los nombres y la obra de Vannevar Bush, Douglas Engelbart, Ted Nelson, Alan Kay, Bill Atkinson y Tim Berners-Lee entre otros, son claves para comprender la llamada "revolución electrónico-informativa".

Desde el "Memex", de V. Bush hasta el WWW de BernersLee, pasarían apenas 38-40 años, pero conceptos como hipertexto, hipermedia y utopías como el proyecto "Xanadú" (la suma total del conocimiento humano por medio de la bilblioteca universal 
hiperenlazada mediante tecnología digital ) de Ted Nelson, invenciones como el mouse y la interface gráfica amistosa de D. Engelbart, las primeras aplicaciones hipertextuales, multimedia e interactivas eficaces como las de B. Atkinson, o el código que dió origen al www, tal como lo conocemos hoy en día gracias a T. Berners-Lee y que son ahora comunes, fueron la aportación enorme de estos personajes al terreno de la visualización.

Desde el célebre artículo de V. Bush "As we may think" en 1945. a la fecha los avances más significativos en interactividad e hipertextualidad se han dado en el terreno de la expansión o aumento de la mente humana, de la memoria y la capacidad de involucrar la habilidad para el asociamiento visual-conceptual, para leer en las imágenes textos y subtextos y crear trayectorias no lineales para la producción de sentido, en síntesis aumentar el poder de la inteligencia humana.

En el dominio plástico obras gráficas o plásticas si se quiere con la intervención de alguna tecnología computacional o parte de ella se remontan a los primeros años 60 , pasando por un período de incubación -maduración que se extiende hasta la segunda mitad de los 80. En todo ello el desmontaje de la linealidad de lectura y concepción es clave, el Digital Art, lleva en su semilla, la génesis de una nueva sintaxis y un nuevo status, a diferencia de otras corrientes contemporáneas como el video arte, el happening o el arte conceptual, que reformaban o contrapunteaban modos (y técnicas) estalecidas de ver, por lo que quizás al principio no existieron grandes personalidades artísticas que incorporaran a su obra plástica, dispositivos y procedimientos de tecnología digital, pero su evidente cualidad democrática estaba enunciando ya rasgos singulares, como la propiedad difusa, colectiva o efímera, la diacronía y el dislocamiento espaciotemporal vía el web o la realidad virtual. Los Media, especialmente los digitales, están aportando la tecnología para transformar y extender las dimensiones del aquí y el ahora, los artistas siempre han participado dinámicamente en la construcción de nuevas formas artísticas que resultan de una nueva percepción de la realidad, del tiempo y el espacio, Peter Weibel lo resume inteligentemente: 
Sabemos que el vínculo común entre los medios tecnológicos/visuales del cine y la fotografía con los medios artísticos de la pintura y la escultura reside en el modo en que se almacena la información visual. Estos vehículos materiales hacen que sea extremadamente difícil manipular esa información. Una vez grabada, la información visual es (era) irreversible. La imagen individual es inmóvil, está congelada, estática. Cualquier movimiento es, como mucho, ilusión (Weibel, 1998).

Con la imagen digital nos colocamos en el extremo opuesto al transformar las imágenes en información binaria es decir en un sistema numérico, y éste en un sistema dinámico, cada componente es ahora variable y adaptable y lo más sorprendente es que permanece editable en cualquier punto de cada uno de sus componentes, la articulación original no reside ya en un espacio físicamente definido, su despliegue en la pantalla, por ejemplo, se dá en un tiempo que no puede ser sistematicamente fijado, la imagen deviene un sistema dinámico, que reclama una revisión absoluta de nuestros preceptos visuales. A través de esta variabilidad instantánea, de la posibilidad de reciclamiento infinito, dislocación de la identidad iconográficaiconológica, se revela la adecuación ideal de la imagen digital para crear entornos virtuales e instalaciones interactivas, un núcleo de sintáxis plástica realmente novedoso.

\section{Dislocación de sentido e identidad}

hacia una visualidad postsimbólica

Si se quiere establecer axiológicamente una base teórica que permita profundizar en el análisis de la visualidad del arte interactivo digital, el Web art, el CD ROM interactivo de arte, la instalación multimedia, etc. necesariamente tendríamos que hablar de interfase e hipertextualidad en un primer momento y de identidad, espacialidad y tiempo en otro.

Interfase es cualquier modalidad que adquieran los dispositivos de "control y comunicación" con las máquinas o instrumentos, en la cultura digital las interfases computacionales, tienen el rasgo 
singular de que entablan una comunicación permanente mientras el equipo opera, esta "conversación", puede asumir distintas modalidades, se estima que la interfase ideal, debe responder a un esquema conversacional igualitario, rompiéndo (por ejemplo) la linealidad del discurso horizontal de un debate; las interfases bien diseñadas, desaparecen del plano perceptivo-operativo (pasando como diría Merleau-Ponty, de ser información espacializada a ser información espacializante). Al respecto investigaciones desarrolladas en el $\mathrm{Me}$ dia Lab. del MIT (Massachussetts Institute of Technology), establecen cinco principios (corolarios, según el léxico particular del Media Lab), que debería en condiciones ideales, cumplir toda interfaz digital bien concebida:

- Interruptibilidad: comunicación mutua y simultánea, en lugar de la alternacia (adelante-atrás, por ejemplo) que responde a esa linealidad secuencial del debate.

- Granularidad: el elemento de interactividad más simple debe ser garantizado en una interacción dada, en una conversación es la palabra, en un libro el capítulo y así sucesivamente.

- Degradación atractiva: debe ser posible dejar en curso una tarea a voluntad o terminarla paralelamente, sin necesidad de perder retroalimentación con la interacción.

- Horizonte limitado: una interacción dada no debería permitir preveer completamente el patrón establecido para la consecución de una tarea. Al contrario en la medida que una experiencia interactiva progresa, nuevas rutas o patrones deberían poder ser calculados sobre la marcha.

- Infinitud aparente: la interfase debería ofrecer un máximo de elecciones al menor nível de granularidad, ofreciendo la impresión de una espacialidad que aumenta a través de una explorabilidad infinita en el seno de un proyecto dado (Toledo Ramírez, 1998).

Hipertexto es ciertamente un concepto que merece siempre mayor atención de la que es posible dedicarle en unas cuantas líneas, más aun cuando la incorporación del mismo a diversos terrenos del conocimiento humano a partir de la segunda mitad de los sesenta se vió incrementada de manera sorprendente. Hipertexto e hipermedia son términos acuñados en esos años por Ted Nelson, para describir 
una manera particular en que los nuevos medios, apoyados en el poder de la computadora para almacenar, recuperar y desplegar información, textual, imágenes, video, sonido y movimiento podrían comportarse.

En el hipertexto el material textual (o informativo), puede ser intervinculado de forma que un vasto sistema de relaciones rompe la lectura lineal, permitiendo manipular la información en una forma más similar a la manera en que el cerebro trabaja asociativamente, tanto T. Nelson como V. Bush y D. Engelbart, basaron sus invenciones en esta idea: la mente humana no trabaja en una forma linealmente jerarquizada, sino por asociaciones contingentes interconectadas, ir a donde se quiere en el nivel que se quiere, empezando por el medio, o el final y terminando al inicio de una obra, esa es la gran aportación de la hipertextualidad, una ruptura espacio-temporal-sintáctica.

Desde una perspectiva personal, hipertexto, identidad y visualización constituyen el eje de conceptualización bajo el que los artistas visuales que trabajan con tecnología digital aportan una percepción y sensibilidad distinta y novedosa, la materia prima de la fotografía y el cine siempre fué el tiempo, la tecnología digital llevó a su extremo natural el time based art, dotando a los artistas de la posibilidad de espacializar virtualmente el contenido más relevante de la información que deviene espectáculo: la identidad hoy derrumbada por la tecnología digital que ha emancipado a la fotografía de una objetividad y realismo más impuesto que real, permitiendo a los artistas conducir su búsqueda de un lenguaje acorde con el zeitgeist actual con la participación de instrumentos poderosísimos en la reconstrucción de una alteridad singular y una identidad mutable y multiple, que posibilita deconstruir y reciclar en un loop infinito todo un vasto imaginario social, una visualización radicalmente nueva.

Según Jaron Lanier (1996), uno de los gurús y padre de la virtual reality y del ciberwear, en un futuro cercano, todo el boom de la realidad virtual y sus imperfectas visualizaciones, de espacios inexistentes, la economía espacio-temporal, el flujo de la información en internet estructurada bajo la lógica peep show pornográfica (pagar más por ver más). El arte digital en diálogo con una estética de la desaparición, terminará por desembocar en una nueva forma de 
comunicación, un lenguaje postsimbólico, donde en lugar de utilizar meramente palabras, se crearán directamente mundos compartidos a través de la programación de escenarios virtuales por ejemplo dos adolescentes entablan una conversación mediante el diseño, programación e interacción de vastos territorios virtuales cuya realidad se supeditará a los desbordes (decosntruidos y reciclados) de ese discurso conversacional, apoyados por una poderosa tecnología de interfase y de lenguajes de programación transparentes, no opacos.

Ellos elaborarán sus discursos manipulando esa tecnología con la misma familiaridad y simplicidad con la que nuestros padres en los sesenta aprendieron (finalmente) a manejar el control remoto de la TV, en los ochentas a programar la videograbadora y utilizar el fax, en los noventas a utilizar su e mail y así sucesivamente...

\section{Bibliografía}

ARNHEIM, Rudolph. 1969. Visual thinking. Berkeley y Los Angeles: University of California Press.

COUCHOT, Edmond.1989. La technologie dans l'art. De la photographie à la réalité virtuelle, Nîmes, Éditions Jacqueline Chambon de una cita por Christine Desrochers, programme de doctorat en sémiotique, Université de Québec au Montréal, De la spécifité sensori-cognitive d'une nouvelle expérience technesthésique: Le site d'art internet, pp 77-84. En Visio, volúmen 5, No. 1, primavera de 2000. La revue de l'Association International de Sémiotique Visuelle.

COTTON, Bob \& OLIVER, Richard.1998.Understanding hypermedia 2000, multimedia origins, internet futures. London, England: Phaidon Press Lid.

DERY, Mark.1998. Velocidad de Escape, la cibercultura en el final del siglo. Madrid, España: ediciones Siruela.

FONTCUBERTA, Joan. 1998. "Después de la fotografía: identidades fugitivas". La revolución digital y sus dilemas, sección Estética y Teoría. Revista El Paseante números 27-28, Madrid, España: ediciones Siruela.

GUASCH, Anna Maria. 2000. El arte último del siglo XX, del posminimalismo a lo multicultural. Madrid, España: Alianza For- 
ma, Alianza editorial.

HELLER, Steven \& DRENNAN, Daniel. 1997. The digital designer, the graphic's artist guide to new media. New York: Watson-Guptill Publications.

IF/THEN PLAY. 1999. A netherlands Design Institute publication, edited by Janet Abrams.

KROKER/KROKER. 1997. Digital delirium. Arthur and Marilouise Kroker editors. New York: St. Martin's Press.

LANIER, Jaron. 1996. A cyberspace renaissance man reveals his current thoughts on the World Wide Web, virtual reality, and other silicon dreams, entrevista con Corey S. Powell web editor de Scientific American, http://www.sciam,com/interview/lanier/ $\underline{\mathrm{html}}$

MAYER FOULKES, Benjamín.1999. "Evgen Bavcar, el deseo de imagen”. Luna córnea, número 17, enero-abril, Méx. DF.

MERLEAU-PONTY, Maurice.1945. Phénoménologie de la perception. Paris: Gallimard, pp. 281-282.

RUSH Michael. 1999. New media in late $20^{\text {th }}$ century art. New York: Thames \& Hudson.

TOLEDO RAMÍREZ, Francisco Gerardo. 1998. "Hipertextualidad, identidad, plagio y neurochips (como intefase utópica) en la cultura digital, sentido deconstructivo, sin sentido constructivo". Semiótica, memoria del grupo de investigación. Juan Manuel López coordinador, Méx. DF.:UAM A, CYAD, Departamento de Evaluación del Diseño.

VISIO. 2000. Volúmen 5, números 1 y 2, primavera/verano. La revue de. L'Association International de Sémiotique Visuelle.

WEIBEL, Peter. 1998. "El mundo como intefaz". La revolución digital y sus dilemas, sección Estética y Teoría. Revista El Paseante, números 27-28. Madrid España: ediciones Siruela

\section{Sitios web relacionados}

GIBSON,W. www.idoru.com/

THE NOOSPHERE AND TEILHARD DE CHARDIN,www.sunangel.com/noosphere/info.html

RUSHKOFF'S, D. Stuff, www.levity.com/rushkoff/index 10.html 
THE MARSHALL MCLUHAN Center on Global Communication, Ww?.mcluhanmedia.com

DELEUZE, G.; GUATTARI, F. www.uta.edu/english/apt/d\&g/ d7gweb.html

BARLOW,J. P. www.eff.org/ barlow/barlow/library.html

LOCHHEAD, D. www.interchg.ubc.ca/dml/tdws.html

LEARY, T. Homepage, www.leary.com

LANIER'S,J. Homepage, www.well.com/user/jaron/index.html

TODAY'S READINGS FOR CYBERSPACE SOCIETY AND CULTURE, umbc 7,umbc.edu/ curnoles/readtoda.html

CYBERSPACE, VIRTUAL REALITY AND CRITICAL THEORY, http://twine.stg.brown.edu/projects/hipertext/landow/cpace/theory/ theoryov.html

THE HYPERMEDIA RESEARCH CENTRE, www.wmin.ac.uk/ media/HRC/manifesto/hmm.1.html

CTHEORY, http://english-server.hss.cmu.edu/ctheory.html

OBORO (Digital and Web Canadian art site), http://www.oboro.net 